\title{
Alternativas no tradicionales de desarrollo rural: la Ruta del Pisco como recurso turístico (valle de Elqui, Chile)
}

\author{
An alternative of rural development: the Rout of Pisco \\ as tourist resource (Elqui Valley, Chile)
}

Pablo Lacoste ${ }^{1 *}$, Sandra Navarrete ${ }^{2}$

\begin{abstract}
RESUMEN
La Ruta del Pisco en el valle del Elqui surge como una propuesta complementaria del turismo de sol y playa y el astroturismo que ya están consolidados en la IV Región de Coquimbo, Chile. Si bien todavía no existe formalmente como ruta, de hecho ha comenzado a funcionar debido a sus considerables recursos: bellezas escénicas, infraestructura, instalaciones, equipamiento y cierta superestructura turística. Esta ruta comprende también el tramo inicial de la antigua ruta del aguardiente que desde La Serena se extendía hasta Potosí y Buenos Aires, con una extensión superior a los 6.000 km, la más antigua ruta comercial terrestre de larga distancia del Cono Sur de América. Con sus fortalezas y debilidades, la organización de estos elementos para crear la Ruta del Pisco puede generar un aporte considerable al desarrollo del enoturismo y el turismo rural, de modo tal de brindar un impulso al desarrollo socioeconómico regional. Se analizan los casos de pisqueras destacadas en la zona, como Los Nichos, Mistral, Capel y Tres Cruces.
\end{abstract}

Palabras clave: Ruta del Pisco, enoturismo, pisqueras.

\section{ABSTRACT}

The Route of Pisco Elqui Valley emerges as a complementary proposal of tourism of sun and beach and astrotourism already bound in the IV Region of Coquimbo, Chile. While not formally exist yet as this route has actually begun to operate due to its considerable resources: scenic beauty, infrastructure, facilities, equipment and certain tourist superstructure. This route also includes the initial section of the old route from La Serena brandy extended to Potosi and Buenos Aires, with an area of over $6,000 \mathrm{~km}$, the oldest terrestrial long-distance trade route of the Southern Cone of America. With its strengths and weaknesses, the organization of these elements to create Pisco Route can generate a considerable contribution to the development of wine tourism and rural tourism, to provide a boost to regional economic development. Pisqueras cases are analyzed in the area such as Los Nichos, Mistral, Capel y Tres Cruces.

Key words: Route of Pisco, wine tourism, pisqueras.

\section{Introducción}

El turismo rural se ha convertido en una nueva área de desarrollo económico y social, complementaria de la actividad agrícola. Cada vez más las comunidades asentadas en las zonas rurales, que tradicionalmente se focalizaron en la producción agropecuaria, han encontrado en el turismo una forma no tradicional de generar ingresos, fortalecer su identidad, y jerarquizar las labores del campo, al valorarlas y abrirlas al contacto directo del público de las zonas urbanas. En este contexto se sitúa la Ruta del Pisco, actividad emergente y complementaria de la producción de aguardiente en la IV Región de Chile.

Teniendo en cuenta la variedad de intereses de los turistas que llegan cada año a las playas de La Serena, la Ruta del Pisco puede entregar satisfacción a buena parte de ellos, sobre todo por brindar experiencias y un mayor conocimiento de la cultura de la vid, el vino y el aguardiente en un pueblo cercano a estos productos y paisajes. Basta señalar que la tradición vitivinícola chilena se remonta al siglo XVI, en los orígenes de la conquista y

\footnotetext{
Instituto de Estudios Avanzados de la Universidad de Santiago de Chile.

2 Departamento de Investigaciones Científicas, Tecnológicas y Vinculación, de la Universidad de Mendoza.

* Autor para correspondencia: Pablo.lacoste@usach.cl
} 
colonización española; esta cultura se ha mantenido vigente hasta la actualidad, como se refleja en la cultura de la apreciación del pisco (aguardiente de vino): con un consumo de 2,1 litros per cápita, Chile representa uno de los más altos niveles del mundo; por este motivo, los poetas consideran que el pisco es el "trago nacional" (Allende, 2003: 23).

En el marco del creciente interés por la gastronomía y la sommelería, junto con la identidad de las comidas y bebidas, la Ruta del Pisco aporta afirmación identitaria al país, el fortalecimiento de la principal Denominación de Origen de América del Sur, y la diversificación de la actividad turística regional. La consolidación del turismo de sol y playa en La Serena constituye una demanda latente que ya está en la zona turística. Sobre esta base se ha puesto en marcha una incipiente propuesta de enoturismo, centrado en las pisqueras del valle del Elqui, que puede experimentar un crecimiento considerable a partir de la estructuración de la Ruta del Pisco, mediante un aprovechamiento sistemático de sus fortalezas, la superación de sus debilidades y la articulación de una propuesta integrada. De esta manera, la ruta puede aportar al desarrollo del turismo rural y el agroturismo en la región (Zamora y Barril, 2006; Lacoste y Zamora, 2010; Bedrich Morales, 2011; Fuller, 2011; Szmulewicz, 2012; Lacoste 2013), en el marco de un proceso mayor de alcance mundial (Elías Pastor, 2006; Díaz Armas, 2008; Marzo-Navarro, 2012).

La futura Ruta del Pisco se apoya en tres fortalezas principales: primero, la consolidación del turismo en La Serena; segundo, las bellezas escénicas del valle del Elqui, a lo largo de la ruta, incluyendo los paisajes de la vid y el vino, y la cordillera de los Andes como majestuoso telón de fondo; y tercero, la presencia de las pisqueras, con sus instalaciones y equipamiento, su ricas historias y su tradición de contacto con el público, aunque sea fundamentalmente espontánea e inorgánica. En cierta forma, la Ruta del Pisco se puede interpretar también como un desarrollo del impacto del turismo de sol y playa, tema que se examina en otras regiones del mundo (Lima, 2013).

La región de Coquimbo cuenta con un mercado turístico que ya está allí, atraído por el turismo de sol y playa, y el astroturismo. Ubicada $450 \mathrm{~km}$ al norte de Santiago (capital del país, con seis millones de habitantes) La Serena se ha convertido en uno de los principales destinos turísticos de Chile; sus playas reciben 600.000 turistas cada verano. Como complemento se ha desarrollado el astroturismo con la Ruta de las Estrellas. Esta actividad contempla la visita a centros astronómicos emplazados en la región como El Tololo, Mamalluca y Collowara, además de ofrecer servicios de trekking nocturno y observación con telescopio profesional, entre otras actividades. La Serena aspira a consolidarse como un referente internacional de astroturismo, al nivel de Canarias y Nueva Zelanda.

La base turística existente en la región constituye una fortaleza considerable para el eventual desarrollo de la Ruta del Pisco, porque ya existe un mercado turístico en el lugar y, además, ya se ha comenzado a construir la cultura de trasladar una parte de ese mercado hacia los valles y montañas interiores, con el astroturismo. En ese sentido, la eventual incorporación de la Ruta del Pisco representaría una propuesta complementaria de las actividades anteriores, y podría contribuir a enriquecer la oferta turística general de la región, al ofrecer la posibilidad de satisfacer necesidades culturales del mercado, sobre todo por el conocimiento de la cultura local, los estilos de vida, las tradiciones auténticas, los paisajes diurnos de los valles transversales. A ello se agrega el atractivo que el enoturismo puede ofrecer a los amantes de los vinos y aguardientes. Existen otros ejemplos en el mundo donde se han desarrollado estos sistemas mixtos. Un caso emblemático se encuentra en las islas Canarias. Tradicional destino de sol y playa, en los últimos años se interesó en enriquecer su propuesta con el astroturismo y el enoturismo (Díaz Armas, 2008). En este caso, la eventual Ruta del Pisco cuenta con una fortaleza considerable por su ubicación geográfica: el camino comienza en las playas de La Serena, toca localidades como Vicuña y Pisco Elqui, con una trayectoria de $100 \mathrm{~km}$ que se recorren en dos horas de viaje. Sobre esta base, se presentan óptimas condiciones para desarrollar una ruta turística activa.

El presente texto constituye una investigación exploratoria de carácter multidisciplinario, considerando aspectos de la historia y de la arquitectura. Las variables de observación se concentraron en el contexto físico que potencia la experiencia del pisco, el paisaje, las expresiones arquitectónicas, el espacio. El enfoque teórico es fenomenológico, es decir, los diferentes niveles de percepción que producen cada una de las variables mencionadas, y cómo las vivencias incrementan la posibilidad de disfrutar a pleno una bebida tan preciada, el pisco. 


\section{La industria del pisco y la ruta del valle del Elqui}

El valle de Elqui, en la región de Coquimbo, articula un conjunto de atractivos turísticos de singular interés: la cordillera de los Andes es el telón de fondo del camino que serpentea junto al río; los paisajes de viñedos en terraza se elevan en las laderas de las montañas; las bodegas y destiladoras artesanales emergen por aquí y allá, aprovechando los espacios y alternando con algunos establecimientos grandes, todo ello en un rico marco cultural, tierra de la mayor poetisa nacional, Premio Nobel de Literatura, Gabriela Mistral. El conjunto de atractivos turísticos naturales y culturales configura una propuesta de interesante diversidad y riqueza identitaria.

En la perspectiva histórica, el valle del Elqui contiene una tradición de más de 400 años en el cultivo de la vid, la elaboración del vino y la destilación de aguardiente. Tras la fundación de La Serena (1544) los colonizadores hispanocriollos se derramaron por estos valles donde pusieron en marcha sus asentamientos agroindustriales. Las características del suelo y el clima facilitaban las condiciones para el cultivo de las uvas criollas (uva de Italia o moscatel de Alejandría; moscatel de Austria, moscatel rosada, entre otras). El mosto se fermentaba en tinajas de greda y el vino se destilaba en alambiques de cobre. El principal mercado se encontraba en Potosí; parte del aguardiente se transportaba en barco de Coquimbo a Arica y de allí en mulas hasta el altiplano. O bien, desde el interior del valle del Elqui, el vino se entregaba a los arrieros que cruzaban la cordillera de los Andes y lo transportaban por el actual noroeste argentino rumbo a Potosí. Esta ancestral historia se consolidó en la cultura y en el paisaje: en cada rincón de la Ruta del Pisco se perciben las huellas de estos siglos de producción, tanto en la arquitectura como en las instalaciones y equipamiento artesanal, y hasta en los nombres de hostales y tabernas. Un claro ejemplo es "La Greda", centro de restauración situado en la ciudad de Pisco Elqui, evocando el nombre original de esta localidad debido a la costumbre de fabricar allí botijas y tinajas para almacenar vinos y aguardientes.

Desde el punto de vista de la producción actual, la industria del pisco se constituye basándose en 10.000 hectáreas de viña, cultivadas por 3.000 pequeños viticultores. La elaboración y comercialización se encuentra en manos de 13 empresas, entre ellas se destacan las dos mayores: Cooperativa Agrícola Pisquera Elqui Limitada (Capel) y la Compañía Pisquera de Chile $(\mathrm{CPCh})$, perteneciente al grupo Lucsik, uno de los mayores conglomerados económicos de la región (con inversiones en minería, finanzas, telecomunicaciones, alimentos y transporte internacional, este grupo supera en la actualidad un capital de USD $\$ 17.000$ millones). Las otras once pisqueras son más pequeñas y algunas son artesanales.

Las viñas y destilerías de pisco se encuentran distribuidas a lo largo de los cinco valles transversales de la zona delimitada en 1931 como Denominación de Origen: Copiapó, Huasco, Elqui, Limarí y Choapa. De los cinco valles dedicados a la producción de pisco las mejores condiciones para desarrollar la Ruta del Pisco se encuentran en el valle del Elqui debido a dos motivos principales: la cercanía del turismo de sol y playa en La Serena y la existencia de cuatro pisqueras abiertas al público. Estas condiciones no aparecen todavía en los restantes valles pisqueros.

\section{Del mar a la montaña: el camino}

La vía de comunicación entre las playas y la zona productiva de Pisco Elqui es una carretera de 100 kilómetros, con múltiples efectos sensoriales, que combinan la imponente presencia del relieve natural y la constante lucha del hombre por domesticar la agreste geografía para extraer de su tierra la noble bebida. Desde la perspectiva fenomenológica se puede notar la variedad de colores que contrastan entre los marrones grisáseos del relieve, los diferentes tonos de verde de la flora autóctona natural y los de los viñedos.

El camino presenta multiplicidad de visiones y perspectivas; la sorpresa es su característica. Se destaca el contraste entre sectores encajonados, que luego de una semioscuridad se abren a escalas naturales colosales, de un valle de gran riqueza, siempre acompañado por el curso del agua. El efecto de la luz es importante, ya que estamos en presencia de uno de los cielos más azules y transparentes del mundo (motivo por el que esta región se ha elegido como sede de observadores astronómicos internacionales). El aire diáfano permite apreciar la belleza escénica, particularmente la multiplicidad de colores de las montañas. En ese sentido, la experiencia de la visita diurna de la Ruta del Pisco 
es un buen complemento de la visita nocturna de la Ruta de las Estrellas.

Junto con las bellezas escénicas, la ruta facilita el descubrimiento de la ancestral cultura local, con sus originales expresiones representadas por pueblos de labradores, pastores y arrieros. Los grupos humanos que habitan el valle del Elqui se expresan mediante formas y prácticas culturales con marcado contenido identitario. Se trata de los protagonistas de los cultivos y la domesticación de un territorio árido y difícil de conquistar. Los diferentes asentamientos revelan el modo de vida propio del lugar, su cultura, su identidad regional. Son pintorescos pueblitos con el majestuoso telón de fondo de la cordillera de los Andes. El contraste entre la naturaleza y la cultura causa un gran impacto en el visitante.

La cartelería situada junto al camino merece una consideración especial. A lo largo de todo el camino aparecen señaléticas que trascienden la información estrictamente vial, y van dirigidas al turista y al consumidor. Son frecuentes los carteles dedicados a promover la Ruta de las Estrellas; en cambio, no existe información relevante y de carácter oficial sobre la Ruta del Pisco. Los carteles dedicados al tema tienen un marcado sesgo comercial y no están bien integrados con el paisaje. Periódicamente aparecen carteles de la marca Triple RRR en estado de abandono; proyectan una imagen de decadencia y descuido. También se puede advertir la presencia de un cartel comercial que promueve la marca de una de las pisqueras, con un diseño totalmente fuera de foco respecto de la cultura y la identidad de lugar. El cartel no muestra rasgos culturales regionales y produce un desagradable impacto visual; parece diseñado por empresas publicitarias especializadas en competir dentro de las grandes megalópolis latinoamericanas, y no en un pintoresco pueblito de montaña. Esta señalética genera un impacto negativo, descontextualizado por el mundo publicitario que permanece al margen de aspectos sensoriales, culturales e identitarios de la región.

Por otro lado aparecen expresiones mucho más adecuadas para la Ruta del Vino, como el uso de toneles reciclados para servir como instalaciones de uso público: paraderos de transporte, pequeños comercios y centros de información. El empleo de estos elementos refleja mayor integración con la cultura del lugar. Lo mismo ocurre con la toponimia y las denominaciones empleadas por emprendimientos turísticos privados, como "La
Greda", que usa una empresa de servicios turísticos, recordando el nombre de ese lugar en el siglo XVIII debido a la producción de botijas, tinajas, como ya se explicó. Otros topónimos evocan la tradición de los pueblos de indios, como "Las Diaguitas", o bien, los accidentes y sufrimientos que debieron enfrentar arrieros y vecinos en los estrechos caminos de montaña, como "Tres Cruces". Estos nombres son emergentes de una larga y auténtica tradición cultural, ello entronca con las expectativas de los enoturistas que recorren el lugar.

En el sector se observan cinco pisqueras relevantes, de diferentes jerarquías, magnitudes, niveles de producción y estado de inserción en el mercado. Las dos primeras representan empresas de gran envergadura, desarrollo edilicio y productivo: Capel y Mistral (CPCh). Otras dos tienen características artesanales en su modalidad productiva y de arquitectura modesta: Los Nichos y $A b a$, esta última en estado de recuperación, luego de un accidente interno. La restante se encuentra en estado inactivo, con interesante potencialidad: Tres Cruces. Se opta por describir los tres ejemplos más representativos, según el orden en que fueron visitados.

Desde el punto de vista de sus dimensiones y significado social, estos emprendimientos representan los distintos niveles involucrados en la industria. El campo popular, comprendido por los pequeños viticultores se manifiesta por medio de la cooperativa Capel. En el otro extremo, las grandes empresas nacionales e internacionales tienen su referente pisquero en la Compañía Pisquera de Chile, y su anclaje local en la Destilería Mistral. En un nivel intermedio, como representante de las Pymes y las tradicionales destilerías artesanales, aparece Los Nichos. Cada uno de ellos entrega su propia mirada y su propuesta cultural.

\section{Lo artesanal: Los Nichos}

Frente a los metarrelatos de la modernidad, signados por la polarización entre el gran capital y los proyectos colectivos, Los Nichos representa la supervivencia de la destilería artesanal, una modalidad de pequeñas y medianas empresas que han logrado mantenerse a flote apoyadas en una secular historia de producción e identidad. La nota dominante de esta pisquera es la escala humana. La construcción principal es un edificio sencillo de dos plantas, que sigue el modelo de la arquitectura 
vitivinícola colonial: la planta superior sirve de residencia familiar y la planta inferior sirve de bodega. Este reducido espacio se halla, a su vez, dividido en dos partes: una dedicada al envasado manual del pisco y otra se emplea como cava para conservar el aguardiente. A su vez, dentro de esta última se ha reservado un lugar como espacio social, un punto de encuentro para los productores y sus amigos: el corazón mismo del emprendimiento y su historia.

En efecto, la cava de Los Nichos se ha transformado en el corazón cultural de la industria del pisco. Este espacio irradia una incontrastable fuerza identitaria, que se proyecta al conjunto de la industria y fortalece toda la propuesta de la Ruta del Pisco. Como indica su nombre, la cava de Los Nichos está decorada con concavidades en forma de nichos de cementerio, que en lugar de cadáveres atesora botellas de vino y aguardiente en un contexto lúdico, completado con murales de esqueletos que bailan y tocan instrumentos musicales, junto con otros dibujos de calaveras y temas alusivos. Se trata de una decoración original, que despierta la atención del visitante. Pero no es mero maquillaje diseñado por un creativo profesional: al contrario, se trata de un patrimonio vivido, con claras muestras de integración con el entorno local y nacional.

La visita a la cava permite a los guías entregar el relato de su historia. Se menciona la figura de Rigoberto Rodríguez Rodríguez, anfitrión de la destilería, este organizaba reuniones sociales en la cava de carácter lúdico. Allí se jugaba al dominó y se realizaban degustaciones de vinos y aguardientes. Había un grupo relativamente habitual de amigos que compartían esas tertulias con actitud irreverente. A cada uno se atribuía la propiedad simbólica de un nicho de esa cava, y en la parte inferior los amigos escribían hipotéticos epitafios, cargados de humor e ironía. En cierta forma, el pisco permitía reírse de la muerte. Al parecer, esta cava adquirió una sólida proyección regional y logró convocar a las más altas figuras nacionales del segundo tercio del siglo XX. Entre sus visitantes se destacan varios presidentes de Chile, como Arturo Alessandri, Juan Antonio Ríos, Pedro Aguirre Cerda y Gabriel González Videla. Ellos formaron parte de la clase dirigente nacional que en su momento se comprometió con el progreso de La Serena, y con el reconocimiento de la identidad del Pisco. Estos relatos aparecen con naturalidad en labios de los guías, el personal de la destilería y los lugareños. Son historias muy antiguas que se han mantenido relativamente intactas a lo largo del tiempo. Un artículo publicado en la prensa regional en 1955 ya daba cuenta de estas prácticas; además, sus descripciones de las instalaciones coinciden casi en detalle con las condiciones en la que la cava de Los Nichos se encuentra en la actualidad, 60 años después (El Regional, Coquimbo, 6 de abril de 1955).

El concepto de la destilería de Los Nichos como patrimonio vivo y vivido se proyecta en el entorno del edificio principal; en los talleres se encuentra un tonelero artesanal practicando su ancestral oficio; en los corrales de alambiques y los edificios anexos se encuentran las instalaciones y equipamiento propios de este tipo de sistema productivo. Lo mismo se percibe en la arquitectura de la sala de ventas y degustación. El conjunto se destaca por su armonía; se muestra con toda la historia a cuestas, sin maquillaje alguno. Se presenta este ejemplo de escala humana y enorme sensibilidad.

La llegada al espacio de la diversión se produce en un ámbito de mediana escala, con un pintoresco mural de carácter pagano, que alude a la muerte en tono de diversión. La presencia de la muerte reflejada en esqueletos no da un marco tétrico, por el contrario, es la desmitificación y la irreverencia de un hecho que es parte de la vida.

$\mathrm{La}$ arquitectura requiere de intervenciones que hagan relevante el importante contenido argumental del recorrido del lugar. Esta pisquera tiene un tesoro cultural, signado por el rico contenido de sus historias mínimas y la autenticidad del relato. Es una propuesta que genera inmediatamente la empatía del visitante, por su originalidad y carácter íntimo y personal.

Paralelamente se detectan algunas debilidades, sobre todo porque no se desarrolla una adecuada estrategia de comunicación de los conceptos y valores de esta pisquera. No se destaca con suficiente claridad el significado del edificio de dos plantas, una para la familia y otra para la producción, estructura propia de la pequeña propiedad y la cultura del trabajo, por oposición del modelo hegemónico en América Latina, signado por los grandes latifundios, el ausentismo y la cultura de la renta. Detrás de este emprendimiento agroindustrial se explica la tendencia chilena a generar una capa de pequeños propierarios rurales, lo que contribuyó al temprano desarrollo institucional de la Nación. Se trata, en cierta forma, de mostrar la identidad de Chile mediante una visita enoturística, que revela un sentido muy profundo en un modesto establecimiento de destilación. 
En resumidas cuentas, Los Nichos exhibe muy claramente sus fortalezas y debilidades: muy buen contenido, en un continente relativamente pobre. De todos modos, la notable riqueza de Los Nichos inclina a pensar que con un diseño y una inversión relativamente acotada se puede generar una cuantiosa valoración de este atractivo turístico.

\section{Lo estético: la Destilería Pisco Mistral}

Notable desarrollo estético alcanza la propuesta turística de la Destilería Pisco Mistral, la marca emblemática de CPCh. Esta empresa tomó el control del sitio en 2006, tras adquirir la cooperativa Pisco Control. Su objetivo fue cambiar la imagen del pisco, asociada muchas veces al consumo popular, para diluir con bebidas gaseosas (piscola). En su lugar, el plan de CPCh fue redefinir el pisco como aguardiente premium, apuntando a una jerarquización del producto. Además de realizar una gran inversión para obtener productos de calidad (la planta de Ovalle), la compañía resolvió establecer un espacio emblemático para proyectar su imagen corporativa, capaz de atraer a los segmentos $\mathrm{ABC} 1$ del mercado. Este fue el objetivo de la Destilería Pisco Mistral, enclavada en la localidad de Pisco Elqui (2006).

En un lugar de larga tradición histórica en la destilación de aguardientes, la nueva empresa se propuso levantar un centro turístico que sirviera de imagen corporativa de todos sus productos pisqueros, incluyendo su marca emblemática, Mistral, y sus opciones alternativas, como Triple $R R R$, Horcón Quemado y Campanario, entre otras. El centro turístico Mistral se distingue por un cuidado minucioso del detalle; se percibe un esmero notable en cada rincón, cada aspecto ha sido planificado, ejecutado y conservado en forma muy profesional, resaltando principios formales y espaciales que refuerzan el sólido carácter de esta instalación.

Resulta notable la articulación de esta destilería con el entorno natural. De todas las destilerías de esta ruta, Mistral se destaca por haber logrado la mejor integración de las bellezas escénicas con las instalaciones pisqueras. No existe un recorte entre la naturaleza y la cultura; al contrario, el diseño ha logrado una transición gradual entre ambas dimensiones. El visitante recorre las cavas, luego transita debajo de los parrales y culmina en un mirador para admirar los paisajes cordilleranos, en un entorno de flora autóctona, cuidadosamente diseñada por expertos paisajistas.

En el manejo de la transición entre la arquitectura y los jardines, un papel destacado cabe al uso de la piedra como material de construcción, junto con el empleo de maderas y evocaciones de tierra cruda. La escala y los escenarios se han trabajado con exquisitos detalles. El tratamiento paisajístico, la vivencia directa de parrones y vegetación autóctona acompañando lugares de disfrute del paisaje hacen que resulte evidente la presencia de arquitectos y paisajistas de alto nivel en el diseño y la ejecución de esta propuesta.

El sector de encuentro y de servicio gastronómico es vivencialmente disfrutado desde las cualidades perceptivas, al haber incluido la vid, las texturas, los contrastes entre luces, sombras y espacios de transición. El empleo de parrones como techumbre natural y el piso empedrado reflejan una voluntad de mantener la armonía del ambiente con la cultura de la vid, el vino y el aguardiente, además de los tradicionales esfuerzos de los productores de la zona de utilizar los materiales disponibles para levantar sus construcciones. Para enfatizar el disfrute de los sentidos se incorpora música en vivo, lo que produce un efecto placentero en el visitante, que asocia descanso con expresiones artísticas, generando recuerdos agradables asociados a la experiencia del pisco.

El espacio de exposición de la industria del pisco es un museo muy bien propuesto, desde lo lumínico, el color, las texturas, el modo de exhibir los elementos propios de la tradición pisquera. Desde el punto de vista técnico, la oferta turística de la Destilería Pisco Mistral exhibe un alto nivel de profesionalismo, guiado por paisajistas y diseñadores profesionales.

Sin embargo, se detecta un hecho curioso: en el centro del relato propuesto por Pisco Mistral se encuentra la historia ya mencionada de Rigoberto Rodríguez Rodríguez. El establecimiento incluye una reproducción de la mesa de juego en la que RRR recibía a sus amigos, rodeado de paredes con nichos ornamentales, para evocar la historia de las tertulias que se realizaban en la cava de Los Nichos. Originalmente, esta tradición tenía todavía más relevancia: el nombre original de la actual Destilería Mistral era, precisamente, Destilería Tres ERRES (Revista Capital, febrero de 2006). Posteriormente, la empresa tomó la decisión de no focalizarse tanto 
en esta marca y cambió el nombre por Destilería Pisco Mistral.

Dentro del museo, el concepto que se explota como propio del carácter de esta pisquera es una historia ajena. La marca "Triple R" fue originalmente creada por la pisquera Los Nichos. En 1993 fue comprada por la Cooperativa Pisco Control. Trece años más tarde, cuando la CPCh adquirió Control, incorporó también los derechos de la marca Triple ERRE y se dispuso a potenciarla. Lanzó entonces una gran campaña de promoción de esta marca, y dispuso la construcción de un elegante centro turístico en Pisco Elqui, llamado "Destilería Triple ERRE", en el que se incluyó un museo inspirado en la cava de Los Nichos, incluyendo una réplica de la mesa en donde Rigoberto Rodríguez Rodríguez se reunía con sus amigos a jugar, degustar piscos y practicar la amistad.

Con posterioridad se presentó un pleito iniciado por la empresa Los Nichos que objetó el uso de su historia en la destilería de la CPCh. Para evitar el conflicto esta empresa tomó la decisión de cambiar su estrategia: desplazó la marca Triple ERRE del centro de su atención y la reemplazó por Mistral. Esta se convirtió en la marca emblemática de la empresa, quedando Triple ERRE en un lugar secundario. Además se cambió el nombre del centro turístico, que pasó a llamarse "Destilería Mistral". Sin embargo, el museo quedó intacto, con el foco puesto en la historia de las tres erres. Y aquí surge la inconsistencia que percibe el visitante actual.

En efecto, la original historia de la cava de Los Nichos no es un elemento más dentro de la propuesta turística de Mistral, sino que se encuentra en el centro de la misma. Llama la atención que esta empresa no haya podido visibilizar algunos aspectos salientes de su propia historia, casi centenaria. Surgido de una cooperativa de centenares de pequeños viticultores, la empresa vivió momentos de tensión dramática e interés humano a lo largo de su trayectoria. En ese sentido, su propia historia tiene, seguramente, elementos de singular valor y atractivo para generar una base sólida para una estrategia de comunicación original y atrayente. En cambio, al enfatizar una historia ajena e invisibilizar la propia, la propuesta de Mistral termina por perder identidad, originalidad y fuerza.

La Ruta del Pisco tiende a promover la comparación entre Los Nichos y Pisco Mistral, debido al discurso de los turoperadores o por la observación personal del visitante. Esto es llamativo, porque se comparan dos empresas de notable asimetría en sus dimensiones, y el balance resulta muy parejo: Mistral parece de muy alta calidad en su continente, pero relativamente pobre en contenido, mientras que Los Nichos exhibe el perfil exactamente opuesto. Es como si uno representara a la mujer más bella, y otro a la mejor maquillada. Más allá de los valores formales y artísticos de Mistral, del análisis crítico surge la necesidad de indagar en rasgos distintivos propios, de microhistorias que se enlacen con Los Nichos, pero con variaciones y aportes que den relevancia a ambos relatos.

\section{Espíritu vanguardista y solidario: Capel}

La infraestructura de este establecimiento tiene sus propios rasgos distintivos. Se destaca como positivo que su identidad no está basada en relatos ajenos. No los desprestigia, por el contrario, los toma como parte de la historia local.

Desde el ingreso se percibe una clara visión en el diseño de imagen corporativa. La arquitectura de rasgos coloniales ha utilizado criteriosamente la tonalidad rojiza, propia de la marca. El estilo neocolonial se entronca con la ancestral tradición de la zona, con sus 450 años de persistencia en el cultivo de la viña, elaboración del vino y destilación del pisco. Además, esta arquitectura se articula muy bien con el paisaje urbano de La Serena, ciudad que se caracteriza, precisamente, por el estilo neocolonial.

Desde el punto de vista de la atención al turista, el establecimiento Capel tiene otra fortaleza considerable: la disponibilidad de una infraestructura específica muy amplia. Tanto la construcción para exposiciones museográficas como el espacio de cafetería y la sala de ventas disponen de cómodos espacios y excelente construcción.

Desde la perspectiva de los encargados de la atención al público y la promoción del turismo de esta empresa, el atractivo principal del establecimiento se encuentra en la planta embotelladora automática. La coordinación de movimientos que se logra para desplazar las botellas por la línea de montaje, el llenado con aguardiente, el etiquetado y embalado en cajas, representa un despliegue tecnológico de notable belleza. Se logra un efecto fascinante, que recuerda el impacto de los ferrocarriles en el siglo XIX: una propuesta de inteligencia desplegada en el espacio, por medio del movimiento mecánico. Una muestra de modernidad en un entorno tradicional 
y artesanal de los valles longitudinales del Norte Chico chileno.

Respecto de la historia misma de la empresa, Capel propone un macrorrelato que se destaca por su épica, por sus valores de solidaridad, y por el esfuerzo de los pequeños viticultores que lograron sostener en el tiempo su identidad y estilo de vida. Frente al auge de las grandes empresas transnacionales y los procesos de concentración de capital, Capel representa la victoria de la solidaridad y la fuerza de los pequeños que se unen para enfrentar a los gigantes. En ese sentido, el relato de Capel se apoya en la épica de 1.200 pequeños viticultores que lograron abrirse camino en un entorno cada vez más hostil y competitivo. La historia de Capel cuenta con una infraestructura turística muy adecuada para entregar un relato de singular fuerza e identidad, capaz de emocionar al visitante, proceso que tendería a concretarse en un aumento de las visitas y de las ventas tanto en el establecimiento como en la etapa posterior, cuando el turista llega de regreso a su lugar de residencia habitual.

Paradójicamente, estas potencialidades no logran articularse en una propuesta atractiva. El visitante de Capel no encuentra un mensaje claro de la historia de la empresa; tampoco vive una experiencia emocionante, a pesar de las magníficas instalaciones disponibles.

Una posibilidad que surge de esta agrupación de cooperativas es encontrar una multiplicidad de microrrelatos que darían una clara visión de la complejidad del accionar de Capel. Su concepción está claramente ubicada en el pensamiento moderno de avanzada en cuanto a propuestas conceptuales y en su admiración por los aspectos industriales, como ellos mismos enuncian como fortaleza: la línea mecánica de embotellamiento.

$\mathrm{Al}$ ingresar al establecimiento (que se distingue de los anteriores por la cordialidad en la atención al público) se perciben contradicciones en las propuestas espaciales de diferentes recintos.

El sector de ventas de los productos que ofrece la marca tiene un carácter poco distintivo de la identidad regional, excede el recurso vanguardista, que no dialoga armónicamente con la propuesta estilística exterior. Para un visitante internacional, este sector trae a la memoria espacios de aeropuertos, en donde se pone énfasis en lo global, por encima de lo regional. Con escasos recursos de texturas y equipamiento podría lograrse una imagen más adecuada.
Algo similar ocurre con el espacio social del encuentro y la degustación. La escala excede de las que se sienten adecuadas a nivel vivencial, los materiales son poco expresivos (como el piso de hormigón) y el mobiliario es escaso, con un carácter más asimilable a los bares de playa que a un sitio auténticamente regional con la mayor envergadura de producción de la zona.

El sector de exposición presenta un acceso interesante, que predispone a la sorpresa y a vivir situaciones de interés, generado por una escalera descendente que remata en un mural de enorme calidad expresiva y evocadora.

Los elementos expuestos son de gran valor patrimonial, pero no se encuentran dispuestos en forma que logren un mayor impacto sensorial y vivencial en el espectador. La idea de comunicar la historia del pisco mediante una línea de tiempo es adecuada, pero no se desarrolla de un modo preciso ni claro. Muchos datos son inexactos. Además, el diseño es pobre y de escasa elegancia.

El espacio físico destinado a museo es generoso, ello evidencia una clara voluntad de lograr una sala de exposición de notable atractivo. Con recursos de luz, color y texturas, manejados con criterios profesionales, podría ser uno de los museos del pisco más importantes de la región.

\section{Otros aspectos relevantes}

Además de la visita a las tres pisqueras principales (Capel, Mistral y Los Nichos), el relevamiento en terreno permitió examinar otros elementos, como el funcionamiento de los turoperadores, el potencial de pisco Tres Cruces y el perfil de Compañía Pisquera de Chile, en Ovalle. A ello se suman las evaluaciones generales de todo el sistema.

Desde este punto de vista, la nota más destacable es la debilidad identitaria del producto. Desde su delimitación en 1931, el pisco representa la Denominación de Origen más antigua de América, la más relevante de América del Sur y una de las más tradicionales del mundo. Esta condición puede ser muy valorada por el consumidor especializado, sobre todo el de origen europeo, debido al notable avance de la cultura de la apreciación de las Denominaciones de Origen que se encuentra instalada en ese continente desde hace siglos. No obstante ello, estos conceptos se encuentran totalmente invisibilizados en toda la ruta; ni los turoperadores, ni las pisqueras ni la cartelería mencionan o informan sobre esta situación. 
Los turoperadores constituyen un sector relevante en el desarrollo de la Ruta del Pisco de Chile. Han articulado una red con capacidad de captar turistas, trasladarlos a lo largo de la Ruta del Pisco y acompañarlos en la visita a las pisqueras. Han realizado un esfuerzo en el diseño de folletería específica que promociona la Ruta del Pisco en los hoteles y hostales de La Serena. De esta forma, los turoperadores han logrado generar un ducto dinámico y activo, que trabaja para convertir un destino turístico de sol y playa, en una propuesta más rica culturalmente, al ofrecer la posibilidad de recorrer la ruta del valle del Elqui.

De todos modos, el funcionamiento de los turoperadores muestra también algunas debilidades considerables. Al parecer, la actividad está poco reglamentada; no existen códigos de ética ni acuerdos generales entre los actores involucrados, para asegurar una atención de mayor calidad al turista. Entre otros detalles, se detectó que el turoperador tiende a llevar al visitante a las pisqueras cuya entrada tiene menores costos (principalmente Los Nichos), y omiten las alternativas más caras (sobre todo Mistral). Por otra parte, el relato que el turoperador entrega a los visitantes se encuentra teñido de enfoques subjetivos, a veces parciales e inexactos. Se detectó, por ejemplo, un discurso muy negativo hacia la propuesta de Mistral, alegando que se trataría de una mera copia de Los Nichos, lo que es inexacto, a la vez que se ocultaba información sobre otros valores de ese establecimiento cuya calidad estética es indiscutible.

El establecimiento de pisco Tres Cruces representa otra muestra el potencial de esta ruta. Se trata de una empresa inactiva para la industria del pisco desde hace largos años, por diversos motivos. Pero el predio cuenta con tres fortalezas notables: la belleza escénica del entorno; la posición privilegiada del terreno, que permite valorar ese atractivo turístico de una forma singular; las casas patronales del establecimiento, que se hallan en muy favorables condiciones y proyectan una imagen de calidez y tradición; las instalaciones de elaboración y destilación, que configuran una sólida base para formular una propuesta atractiva; $y$ una marca con notable fuerza identitaria (Tres Cruces). Desde la perspectiva del futuro desarrollo de la Ruta del Pisco, la puesta en valor de Pisco Tres Cruces sería un valioso aporte.

\section{Conclusión}

La eventual creación de la Ruta del Pisco en el valle del Elqui cuenta con un conjunto de fortalezas que facilitarían su desarrollo, junto con algunas debilidades que pueden frustrarlo. La identificación de estos elementos puede constituir una buena base para la puesta en marcha de la iniciativa.

Entre las fortalezas se destacan: la cercanía de un potencial mercado turístico en la exitosa propuesta de sol y playa en La Serena; las bellezas escénicas del vitipaisaje y la cordillera de los Andes; las instalaciones y equipamientos turísticos aportados por las pisqueras abiertas al público y las redes de servicios de hospedaje y restauración; junto con la tradición de los turoperadores en el desarrollo espontáneo de esta ruta. Dentro de estas fortalezas se distinguen tres pisqueras principales: Los Nichos, con su propuesta atrayente basada en una historia ancestral, original, auténtica y profundamente arraigada, la que se basa en una historia mínima que conmueve y emociona al visitante (RRR); Pisco Mistral, con su ambiciosa propuesta paisajística y su refinada puesta artística; y Capel, con sus excelentes instalaciones y generosos espacios dedicados a recibir al turista.

Junto con las fortalezas se detectan debilidades considerables. La acción de los turoperadores resulta contradictoria y, por momentos, disfuncional al desarrollo del conjunto de la ruta, por prevalencia del interés individual del guía por sobre el conjunto de la propuesta. No existe un estándar mínimo consensuado por los diversos actores involucrados para fortalecer la ruta como un producto unitario. Por otra parte, las propuestas de las pisqueras exhiben también sus debilidades; Los Nichos muestra fortaleza en identidad, originalidad; pero es débil en su continente y su comunicación; Mistral exhibe el cuadro exactamente opuesto: excelente continente con débil contenido. Por último, Capel se siente importante en su megarrelato, y trata de seducir con su mecanizada planta de embotellamiento y su infraestructura turística de gran escala, pero falla en el aprovechamiento de esos espacios y en trascender los valores de la modernidad, para comunicarse en un lenguaje más amigable para el turista, que es más sensible a las historias mínimas y a los valores de la posmodernidad. 


\section{Literatura Citada}

Allende, I.

2003. Mi país inventado. Areté, Barcelona, 224 p.

Bedrich Morales Gaitán, S.

2011. Turismo en espacios rurales de Perú ¿La encrucijada entre el economicismo y la sostenibilidad? Estudios y Perspectivas en Turismo, 20 (3): 609-626.

Díaz Armas, R.J.

2008. Potencialidad e integración del 'turismo del vino' en un destino de sol y playa: el caso de Tenerife. Pasos. Revista de Turismo y Patrimonio Cultural, 6 (2): 199-212.

Elías Pastor, L.

2006. El turismo del vino. Otra experiencia del Ocio. Universidad de Deusto, Bilbao, $256 \mathrm{p}$.

Fuller, N.

2011. Reflexiones sobre el turismo rural como vía de desarrollo: El caso de la comunidad de Antioquía, Perú. Estudios y Perspectivas en Turismo, 20 (4): 929-942.

Lacoste, P.; Jiménez, D.; Castro, A.; Rendón, B.; Soto, N.

2013. A binational Appellation of Origin: Pisco in Chile and Peru. Chilean Journal of Agricultural Research 73, 4: 424-429.

Lacoste, P.; Zamora, J.

2010. “Turismo del vino en Chile: aspectos sociales". Duhart, Frédéric y Corona Páez, Sergio. Los vinos de Europa y América. Catorce miradas desde las ciencias del hombre. Éditions Le Manuscrit, Paris, pp. 179-203.
Lima Barros de Moraes, L.B.

2013. Impactos del turismo de sol y playa en el litoral sur de Sergipe, Brasil. Estudios y Perspectivas en Turismo, 22 (3): 526-545.

López Guzmán, T.J.; Lara de Vicente, F.; Merinero, R.

2006. Las rutas turísticas como motor de desarrollo económico local. La ruta del Tempranillo. Estudios Turísticos, 167: 131-332.

Marzo-Navarro, M.; Pedraja-Iglesias, M.

2012. Desarrollo del turismo del vino desde la perspectiva de los productores: una primera aproximación al caso de Aragón - España. Estudios y Perspectivas en Turismo, 21 (3): 585-603.

Mitchell, J.T.; Terry, W.C.

2011. Contesting Pisco: Chile, Peru and the politics of trade. The Geographical Review, 101 (4): 518-535.

Szmulewicz E,P.; Gutiérrez V,C.; Winkler Ch., K.

2012. Asociatividad y agroturismo: Evaluación de las habilidades asociativas en redes de Agroturismo del sur de Chile. Estudios y Perspectivas en Turismo, 21 (4): 1013-1034.

Zamora, J.; Barril, M.E.

2007. Un estudio formativo para la evolución de las rutas del vino en Chile. Estudios y Perspectivas en Turismo, 16 (2): 173-194. 